\title{
Article \\ Sustainable Project Management: Reducing the Risk of Cost Inaccuracy Using a PLS-SEM Approach
}

\author{
Ali Foroutan Mirhosseini ${ }^{1,2, *(\mathbb{D})}$, Kelly Pitera ${ }^{1}\left(\mathbb{D}\right.$, James Odeck $^{1,3}$ and Morten Welde ${ }^{1}(\mathbb{D}$ \\ 1 Department of Civil and Environmental Engineering, Norwegian University of Science and Technology, \\ 7491 Trondheim, Norway; kelly.pitera@ntnu.no (K.P.); James.odeck@ntnu.no (J.O.); \\ Morten.welde@ntnu.no (M.W.) \\ 2 Norwegian Public Roads Administration, 7075 Tiller, Norway \\ 3 Norwegian Public Roads Administration, 0609 Oslo, Norway \\ * Correspondence: Ali.mirhosseini@ntnu.no; Tel.: +47-45869767
}

check for updates

Citation: Foroutan Mirhosseini, A.; Pitera, K.; Odeck, J.; Welde, M. Sustainable Project Management: Reducing the Risk of Cost Inaccuracy Using a PLS-SEM Approach.

Sustainability 2022, 14, 960. https:// doi.org/10.3390/su14020960

Academic Editors:

Isabel Ortiz-Marcos and

Rocío Rodríguez-Rivero

Received: 26 November 2021

Accepted: 12 January 2022

Published: 15 January 2022

Publisher's Note: MDPI stays neutral with regard to jurisdictional claims in published maps and institutional affiliations.

Copyright: (C) 2022 by the authors. Licensee MDPI, Basel, Switzerland. This article is an open access article distributed under the terms and conditions of the Creative Commons Attribution (CC BY) license (https:/ / creativecommons.org/licenses/by/ $4.0 /)$.

\begin{abstract}
Determining the factors leading to cost inaccuracy in infrastructure projects relates to sustainability by improving the cost performance of the projects (economic sustainability) and reducing the waste of available resources (environmental sustainability). This study investigates the effects of various factors affecting the cost performance of large-scale road projects in Norway in both the planning and construction phases. To this aim, a quantitative approach using a questionnaire survey was employed to understand the attitude of practitioners towards various factors causing cost increases. An advanced multivariate statistical approach of Partial Least Square Structural Equation Modeling (PLS-SEM) and Relative Importance Index (RII) was utilized to analyze the questionnaire responses. The results of the RII analysis show that local wishes, defective estimations, and long processing times had the most impact on the cost increase during the planning phase. At the same time, scope changes, market conditions, and unforeseen ground conditions were the most influential parameters in the construction phase. Moreover, the results obtained from PLS-SEM reveal that external related factors had the most influence among the other grouped factors (i.e., pre-construction, project management and contractual relationship, contractor's site management, and external) on cost overrun during the construction phase. Increasing the knowledge of these factors will allow for developing relevant project management approaches targeted at improving economic and environmental sustainability within both the planning and construction phases.
\end{abstract}

Keywords: cost overrun; PLS-SEM; project management; sustainability; Norway

\section{Introduction}

Transportation infrastructure is a key element in the development of countries, and the demand for such infrastructure is increasing, while the economic and material resources available are diminishing. Recently, increased attention has been paid to needs analysis, planning procedures, budget allocation, and the performance of projects to make sure that the right projects are selected for implementation, and that the projects are delivered in a sustainable and efficient way.

\subsection{Problem Statement}

Sustainability continues to attract considerable attention in many domains, including project management. Sustainability stands on the three pillars (i.e., social, environmental, economic) of the well-known "three P" concept (People, Planet, Profit), which are interrelated and affect each other [1]. To relate sustainability to project management, one should consider aspects that can be addressed by sustainability considerations, including human resources management, procurement, communications, and risk management [1]. As sustainability in the field of project management has developed, economic sustainability is now being interpreted as a success factor in projects [1,2]. 
While economic sustainability is a concern within infrastructure project management, most transportation projects are not monetarily profitable alone, and are often undertaken for additional political and/or social reasons [3]. In addition, many large infrastructure projects around the world are not completed within their cost- or timeframe, further exacerbating cost efficiency problems. The weak cost performance of a project can be considered as a failure in project management, since traditionally project success has been linked to high efficiency in the three main aspects of scope, time, and cost, known as the golden triangle [4]. Therefore, determining and eliminating the risk factors that reduce efficiency in any of the mentioned aspects (risk factors) can significantly improve the level of project success [5,6], and thus improve economic sustainability.

\subsection{Knowledge Gap}

The literature in the field of cost overrun/cost performance of infrastructure projects has been primarily focused on the construction phase and on project-specific factors, which can affect the cost performance of the project during the construction phase, including project size, project type (e.g., road, rail, etc.), project completion time length, the geographical area in which project is constructed, etc. [1-5,7-9]. However, while less studied, aspects of the planning phase are also suggested to significantly affect cost inaccuracies in project governance [4]. During the planning phase, many factors can affect the project idea, and the direction in which the project concept evolves. Consequently, initial scope and cost estimations may change and escalate, respectively. Odeck believes cost escalation during the planning phase can be even higher than that of the construction phase [9]. Moreover, factors affecting cost performance during the planning phase may indirectly affect the construction phase. Thus, further research into planning phase factors and their relevance to the overall cost performance of the infrastructure projects contributes to the body of literature on cost efficiency and economic sustainability within project governance.

\subsection{Research Aim}

Cost inaccuracy poses a risk to the sustainable implementation of infrastructure projects. Therefore, determining the parameters affecting cost accuracy will not only improve the cost performance of the project and result in economically sustainable project management, but can also result in the better use of resources and thus further preservation of the environment $[1,5,6]$.

The aim of this paper, therefore, can be expressed in two main research questions:

1. What are the main factors affecting cost inaccuracy during the planning and construction phases?

2. How can different groups of risk factors (constructs) affect cost inaccuracies during the construction phase?

The importance of this study is that the Norwegian Public Roads Administration (NPRA) has reformed and revised the structure of planning and surveillance in the planning process of the large-scale road projects from 2000 in order to curb cost overruns. Hence, this study gives insight into the current challenges in the planning and construction of large-scale road projects, and helps the NPRA to both evaluate the efficiency of the modified program and improve the current system. This is particularly relevant given that recently, the sustainable development of projects has become one of the top goals of the NPRA [7]. The data were gathered via questionnaires, and based on the obtained results, factors in both planning and construction stages were ranked according to their importance. The influential factors in the construction phase were categorized into four main constructs (i.e., external, contractor's site management, pre-planning, and project management and contractual relationship). A full model for cost increase was constructed and empirically validated using the PLS-SEM approach. Studies that have examined the causes of cost increase using the PLS-SEM methodology are scant in the literature. Evaluating these factors can present the current challenges in cost performance evaluation in a larger aggregated picture. It is important to note that this type of study should be done in individual countries, as using 
international results may create the risk of fallacies in the interpretation of statistical data. However, the methodology used in this study is still valid for similar studies worldwide, and the results can inform the development of other studies.

\subsection{Organization of the Paper}

The rest of this paper is organized as follows: Section 2 gives an overview on the concept of cost overrun and the relevant studies; Section 3 describes the methodology of the paper, including the main factors affecting cost increase and overrun in the planning and construction phases, respectively, as well as data collection, and describes the concept and the methods used to analyze and interpret the data; Section 4 presents and synthesizes the results. Section 5 discusses the obtained results, and finally, Section 6 summarizes the study's conclusions within the context of the field.

\section{Literature Review}

The positive difference between actual costs minus estimated costs (in net present value) within the construction phase is called cost overrun. The difference between actual costs and estimated costs can be expressed as a percentage of estimated costs, and is called percentage cost overrun [8-11]. There is a variety of research addressing the issue of cost overruns. Early studies concentrated on the prevalence, magnitude, and percentage of cost overrun [12-15]. Despite differences in their findings, which could be attributed to several factors including geographical area, type of the project, sample size, use of nominal or real prices, methods of calculation, and considering different moments for estimated and actual costs, almost all the studies agree that cost overrun is prevalent, but the magnitude varies from one project to another [8]. Later, studies aimed to focus on the causes and explanations of cost overrun, in addition to the magnitude and the percentage of cost overrun [16-19]. A study within this group by Cantarelli et al. [20] categorized the explanations for cost overrun into four main categories: technical, economical, psychological, and political. Other research has evaluated the causes of/factors affecting cost overrun using questionnaires or surveys. These studies are primarily case-specific/individual, and are limited to a specific country/region [21,22]. However, there is a lack of studies on the identification of root causes of overruns within specific countries. As mentioned, most of the studies have either evaluated cost overrun in large sample sizes around the world, or focused on the magnitude and determinants of cost overrun. Evaluating the causes of cost overrun within specific countries can give a better understanding of the current situation of the project governance and cost performance of the projects. Moreover, since the results of one specific country may not be applicable for other countries, carrying out case study research within specific countries may provide valuable knowledge for organizations responsible for the planning, estimation, and delivery of large projects.

On the other hand, the literature indicates that significant cost increases often occur during the planning phase; thus, to gain a better understanding of a project's cost performance, early planning phases must be taken into consideration [19,20,23]. Cost overrun in the planning phase is commonly considered a "cost increase" or "cost escalation". When the cost estimates are not precise, the wrong project may be decided upon, and later managing the project, especially large-scale projects, will be difficult, likely leading to cost overruns [24]. However, if estimations are accurate and the actual costs are known to the decision-makers, they may choose more profitable projects, modify the current proposal, or invest the budget elsewhere [15]. For instance, Welde and Odeck [23] found that cost estimates used in final investment decisions have gotten more accurate in the past decade in Norway. However, the estimates in the planning stages have been significantly underestimated. They largely suggest that project governance and the role of project ownership should be improved, cost-benefit and ex-post evaluations should be increased, and in general, cost estimations in the planning stages should be further investigated. Therefore, it can be inferred that unlike cost overrun during the construction phase, research on the most important causes of cost increase in the planning phase is scant. 


\section{Methodology}

\subsection{Identifying the Causes of Cost Overrun in the Construction Phase}

Within this study, it was necessary to identify potential causes of both cost increase and cost overrun, to be used within the questionnaire. A comprehensive literature review was carried out to identify the major factors affecting cost overrun during the construction phase. The thirty most common and frequently occurring causes are presented in Table 1. In addition, the two additional factors of project size (budget) and length of the road were added to the initial factors, according to the author's experience and previous studies, resulting in 32 factors considered in the study.

\subsection{Identifying the Causes of Cost Increase in the Planning Phase}

As there is less existing research on overruns within the planning phase, the identification of potential causes affecting cost increase was carried out through both literature reviews and also two explorative semi-structured interviews with two project teams responsible for implementing two large-scale (budgets more than EUR 75 million) road projects in Norway. The semi-structured interviews identified 18 different causes affecting cost increase during the planning phase, as presented in Table 2. QA1 and QA2 (as seen in the table) indicate two different steps in the Quality Assurance regime introduced and financed by the Ministry of Finance for planning, financing, and implementing large public projects. The main goals of the QA process are to ensure that projects result in more benefits, lower overruns, and improved performance [23]. 
Table 1. Thirty factors affecting cost overrun in the construction phase (from literature review, without two additional complementary parameters).

\begin{tabular}{|c|c|c|c|c|c|c|c|c|c|c|c|c|c|c|c|}
\hline \multirow{2}{*}{ Factor } & \multicolumn{15}{|c|}{ Study } \\
\hline & [25] & [26] & [27] & [28] & [29] & [30] & [31] & [32] & [33] & [34] & [35] & [36] & [37] & [38] & [39] \\
\hline 1- Insufficient site management and inspection & $\bullet$ & $\bullet$ & & $\bullet$ & & & & $\bullet$ & $\bullet$ & & $\bullet$ & • & $\bullet$ & & \\
\hline 2- Forecasting erx7rors (e.g. increasing prices) & & $\bullet$ & & & & & & & & & & & & $\bullet$ & \\
\hline 3- Poor project design & $\bullet$ & $\bullet$ & & $\bullet$ & & & & $\bullet$ & & • & & $\bullet$ & • & & - \\
\hline 4- Scope changes & & & $\bullet$ & $\bullet$ & $\bullet$ & & $\bullet$ & $\bullet$ & $\bullet$ & & & & $\bullet$ & $\bullet$ & $\bullet$ \\
\hline 5- Labor Unavailability or lack of skilled labor & & $\bullet$ & $\bullet$ & $\bullet$ & & & $\bullet$ & & $\bullet$ & & $\bullet$ & & & & \\
\hline 6- Improper scheduling & $\bullet$ & $\bullet$ & $\bullet$ & • & & & & & & & & & & & \\
\hline 7- Lack of experience (in handling such projects) & $\bullet$ & $\bullet$ & $\bullet$ & & & $\bullet$ & & $\bullet$ & & $\bullet$ & $\bullet$ & $\bullet$ & $\bullet$ & $\bullet$ & $\bullet$ \\
\hline 8- Effect of bad weather (climate) & $\bullet$ & $\bullet$ & $\bullet$ & $\bullet$ & $\bullet$ & $\bullet$ & & & $\bullet$ & $\bullet$ & $\bullet$ & $\bullet$ & $\bullet$ & $\bullet$ & $\bullet$ \\
\hline 9- Unforeseen ground conditions & • & & & & & & & • & $\bullet$ & & • & & & & \\
\hline 10- Delay in progress payment by the owner & $\bullet$ & $\bullet$ & & & $\bullet$ & & $\bullet$ & $\bullet$ & $\bullet$ & $\bullet$ & $\bullet$ & & $\bullet$ & $\bullet$ & \\
\hline 11- Poor in-site financial control & & & - & & & & & & & & & $\bullet$ & • & & \\
\hline 12- Low labor productivity & & $\bullet$ & & & $\bullet$ & & & & & $\bullet$ & $\bullet$ & $\bullet$ & & $\bullet$ & \\
\hline 14- Poor project management & $\bullet$ & & $\bullet$ & $\bullet$ & $\bullet$ & & & & & & $\bullet$ & & $\bullet$ & & \\
\hline 15- Delays in decision-making & $\bullet$ & $\bullet$ & & & & $\bullet$ & $\bullet$ & $\bullet$ & $\bullet$ & $\bullet$ & $\bullet$ & $\bullet$ & $\bullet$ & & $\bullet$ \\
\hline 16- Market conditions & & $\bullet$ & $\bullet$ & & $\bullet$ & $\bullet$ & $\bullet$ & $\bullet$ & & $\bullet$ & & & $\bullet$ & $\bullet$ & $\bullet$ \\
\hline 17- Inefficient use of resources & & $\bullet$ & & $\bullet$ & $\bullet$ & & & & $\bullet$ & & & $\bullet$ & & & \\
\hline 18- Rework due to poor material quality & $\bullet$ & & $\bullet$ & $\bullet$ & $\bullet$ & $\bullet$ & $\bullet$ & & & $\bullet$ & $\bullet$ & $\bullet$ & & & $\bullet$ \\
\hline 19- Strategic behavior (deliberate behavior) & $\bullet$ & $\bullet$ & & $\bullet$ & & & $\bullet$ & & $\bullet$ & & & $\bullet$ & & & $\bullet$ \\
\hline 20- Deliberate underestimation of costs & $\bullet$ & & $\bullet$ & $\bullet$ & & & & $\bullet$ & & & & $\bullet$ & & & $\bullet$ \\
\hline 21- Lack of incentives & & & $\bullet$ & & & & $\bullet$ & $\bullet$ & $\bullet$ & & & & & $\bullet$ & \\
\hline 22- Inadequate planning process & $\bullet$ & $\bullet$ & $\bullet$ & $\bullet$ & $\bullet$ & & $\bullet$ & & $\bullet$ & $\bullet$ & $\bullet$ & $\bullet$ & $\bullet$ & & $\bullet$ \\
\hline
\end{tabular}


Table 1. Cont.

\begin{tabular}{|c|c|c|c|c|c|c|c|c|c|c|c|c|c|c|c|}
\hline \multirow{2}{*}{ Factor } & \multicolumn{15}{|c|}{ Study } \\
\hline & [25] & [26] & [27] & [28] & [29] & [30] & [31] & [32] & [33] & [34] & [35] & [36] & [37] & [38] & [39] \\
\hline 23- Lack of resources & $\bullet$ & & & & $\bullet$ & & & & & & & & & & \\
\hline 25- Monopolization of special equipment & & $\bullet$ & & & $\bullet$ & & & & $\bullet$ & & $\bullet$ & & & $\bullet$ & \\
\hline 26- Lack of/Slow communication between parties & $\bullet$ & & & $\bullet$ & $\bullet$ & $\bullet$ & $\bullet$ & $\bullet$ & & $\bullet$ & $\bullet$ & $\bullet$ & $\bullet$ & & $\bullet$ \\
\hline 27- Contractual claims (cost or time extension) & & & $\bullet$ & $\bullet$ & & & & & & & $\bullet$ & & & & $\bullet$ \\
\hline 28- Terrain condition & $\bullet$ & $\bullet$ & & & & $\bullet$ & $\bullet$ & & & $\bullet$ & & $\bullet$ & $\bullet$ & $\bullet$ & \\
\hline 29- Land and property acquisition challenges & & $\bullet$ & $\bullet$ & & & & & $\bullet$ & & & $\bullet$ & & & & $\bullet$ \\
\hline 30- Conflicts between contractor and the owner & $\bullet$ & & $\bullet$ & $\bullet$ & $\bullet$ & $\bullet$ & & $\bullet$ & $\bullet$ & $\bullet$ & $\bullet$ & $\bullet$ & $\bullet$ & $\bullet$ & $\bullet$ \\
\hline
\end{tabular}


Table 2. Factors affecting cost increase in the planning phase.

\begin{tabular}{ll}
\hline \multicolumn{1}{c}{ Num. } & \multicolumn{1}{c}{ Factor } \\
\hline 1 & Local wishes without cost responsibility \\
2 & Defective estimation \\
3 & Long processing time \\
4 & Those who get the benefit are not the ones who pay \\
5 & Changes in rules and regulations \\
6 & Project optimism \\
7 & Poor project management \\
8 & Lack of follow-up \\
9 & Changes in the society expectations \\
10 & City projects are detailed and costly to estimate \\
11 & Different degrees of maturity before QA1 \\
12 & Cost increases from QA1 to QA2 have no consequences \\
13 & Technological development \\
14 & Weak incentives to reduce planning time \\
15 & Little transparency \\
16 & “Value for money” is of little importance \\
17 & Increased funding hides cost growth \\
18 & Changed/different staffing \\
\hline
\end{tabular}

\subsection{Data Collection}

Questionnaire surveys are among the best means of obtaining information from individuals about themselves or something they belong to or are involved in [40]. In this study, a structured questionnaire survey was utilized for data collection, including three main parts: (1) demographics related to professional experience, (2) defining the importance of factors affecting the cost increase in the planning phase (planning factors (PF)), and (3) defining the importance of factors affecting the cost overrun in the construction phase (construction factors (CF)). The early stages of planning (i.e., the planning phase) include problem determination, recognition of the concept, rough cost estimations, and initial planning until the moment of formal decision-making. The construction phase is from the moment of decision-making and budget allocation until the project is finished and is opened for service. The survey was distributed among owners, contractors, consultants, researchers, and project economists working within the transport infrastructure throughout Norway. Respondents were asked to answer the survey only if they were involved in at least one large-scale road project in their career and were able to consider project-specific factors. A total of 119 surveys were sent by e-mail, and 33 completed survey sets were received back and considered for further analysis, indicating a response rate of $28 \%$.

Figure 1 presents the valid responses according to sector, region, years of experience, and profession. As seen, $62 \%$ of the respondents were from the public sector, which owns and maintains the roads in the whole road network in Norway. Half of the respondents are from the East region of the country, which together with the West constitute $67 \%$ of the responses. This was expected, since these two regions are densely populated and comprise almost $70 \%$ of the population. All the respondents have had more than 5 years' experience, and $63 \%$ have more than 15 years. Finally, consultants, researchers, and project leaders were the main three groups of respondents, while no contractors or project economists responded to the survey. 


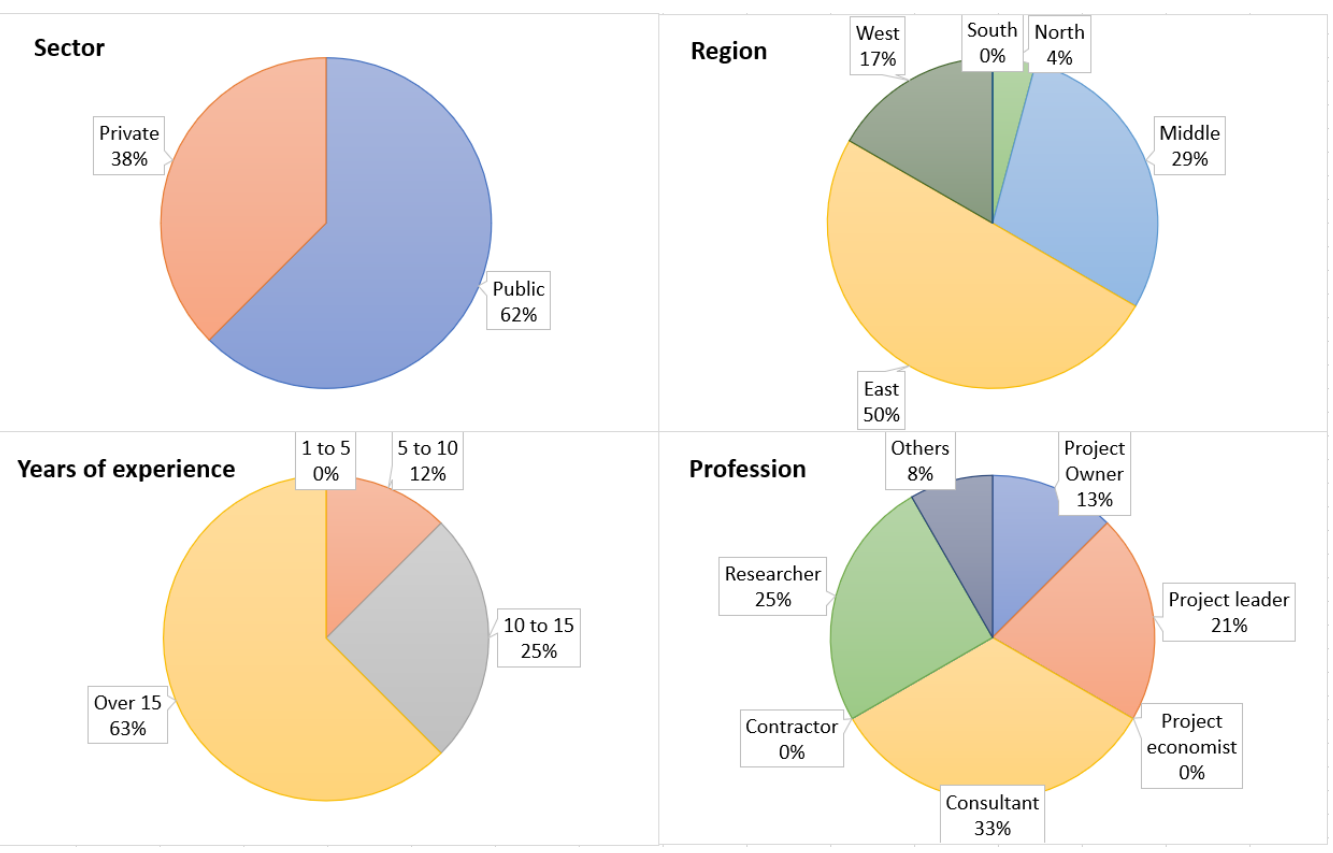

Figure 1. Categorization of respondents $(\mathrm{N}=33)$ by sector, region, years of experience, and profession.

\subsection{Data Analysis}

As mentioned before, the survey considers cost increase/overrun factors for both planning and construction phases (18 and 32 factors, respectively), which were collected from a literature review and in-depth interviews. The respondents were asked to give their opinion regarding the impact of each factor on cost increase/overrun by choosing the correspondent number from a five-point Likert scale, where $1=$ strongly disagree, 2 = disagree, 3 = neither agree nor disagree, $4=$ agree, and $5=$ strongly agree (that the factor impacted project increases/overruns).

In order to analyze the data obtained from the received surveys, SPSS version 25.0 was first utilized to process the descriptive statistics and perform a reliability analysis on the collected data, and to examine the internal consistency of the survey (e.g., PFs and CFs). Internal consistency reliability is a means to assess how well a survey is designed and thus measures what is intended. Cronbach's coefficient $\alpha$, which is explained below, is one of the most accepted measures for determining the consistency level of the survey [41]. After measuring the consistency of the survey to be acceptable, the Relative Importance Index (RII) was utilized to determine the importance of PFs and CFs in a range of 0.0-1.0, where an RII value closer to 1 indicates higher importance [30]. The RII is calculated as follows:

$$
R I I=\frac{\sum_{i=1}^{5} W_{i}}{A \times N}
$$

where $W$ is the weight given to each factor by respondents, $A$ is the highest weight (5), and $N$ is the total number of respondents.

After this, the construction phase was analyzed in more detail. Construction factors or factors affecting cost increase during the construction phase (CFs) were categorized into four main constructs, including Contractor's Site Management (SM), Pre-construction Phase (PC), External (EX), Project Management and Contractual Relationship (PM), as seen in Table 3. They were then coded for further analysis [41,42]. The main reason for doing so was to evaluate the impact of each group of factors in an aggregated way, which can give a better understanding of the larger issues of cost overrun in the construction phase, thus identifying areas for further study. Categorization of the factors was carried out based on the literature review and the author's knowledge. 
Table 3. Causes of cost overrun during the construction phase.

\begin{tabular}{|c|c|c|}
\hline Construct & Abbreviation & Description \\
\hline \multirow{9}{*}{ External } & EX1 & Labor unavailability or lack of skilled labor \\
\hline & EX2 & Effect of bad weather (climate) \\
\hline & EX3 & Unforeseen ground conditions \\
\hline & EX4 & Market conditions \\
\hline & EX5 & Lack of resources \\
\hline & EX6 & Monopolization of special equipment \\
\hline & EX7 & Terrain condition \\
\hline & EX8 & Length of the road \\
\hline & EX9 & Project size \\
\hline \multirow{6}{*}{$\begin{array}{c}\text { Pre-construction } \\
\text { Phase }\end{array}$} & PC1 & Forecasting errors (e.g., increasing prices) \\
\hline & PC2 & Delays in decision-making \\
\hline & PC3 & Strategic behavior (deliberate behavior) \\
\hline & PC4 & Deliberate underestimation of costs \\
\hline & PC5 & Inadequate planning process \\
\hline & PC6 & Land and property acquisition challenges \\
\hline \multirow{9}{*}{$\begin{array}{c}\text { Project } \\
\text { Management and } \\
\text { Contractual } \\
\text { Relationship }\end{array}$} & PM1 & Poor project design \\
\hline & PM2 & Scope changes \\
\hline & PM3 & Improper scheduling \\
\hline & PM4 & Delay in progress payment by the owner \\
\hline & PM5 & Changes in material types and specifications \\
\hline & PM6 & Poor project management \\
\hline & PM8 & Lack of/slow communication between parties \\
\hline & PM9 & Contractual claims (cost or time extension) \\
\hline & PM10 & Conflicts between contractor and the owner \\
\hline \multirow{8}{*}{$\begin{array}{l}\text { Contractor's Site } \\
\text { Management }\end{array}$} & SM1 & Insufficient site management and inspection \\
\hline & SM2 & Lack of experience (in handling such projects) \\
\hline & SM3 & Poor on-site financial control \\
\hline & SM4 & Low labor productivity \\
\hline & SM5 & Inefficient organizational structure \\
\hline & SM5 & Inefficient use of resources \\
\hline & SM6 & Rework due to poor material quality \\
\hline & SM7 & Lack of incentives \\
\hline
\end{tabular}

Within the further consideration of the construction phase, Convergent Validity (CV), which is a measure for determining the internal consistency of the CFs' constructs, was determined using Cronbach's coefficient $\alpha$, Composite Reliability (CR) scores, and Average Variance Extracted (AVE) $[41,43,44]$. Cronbach's $\alpha$ is a reliability measure for the data, and $\mathrm{CR}$ is a measure that determines to what extent a construct is measured by its assigned indicators. They both are used to determine the internal consistency of the constructs, and the difference is that Cronbach's $\alpha$ does not consider factor loading and weighs all the items equally. In contrast, CR considers the item loadings within the theoretical model [41]. It is usually recommended that both Cronbach's $\alpha$ and CR be higher than 0.7 for a highly internally consistent construct. AVE is another measure for determining internal consistency, which is a measure of the amount of variance that is captured by a construct in relation to the amount of variance due to measurement error. As a rule of thumb, AVE should be higher than $0.5[41,42,45]$. This indicates that the latent variables capture more than $50 \%$ of measurement variance.

Structural Equation Modeling (SEM) was first considered to determine the perceived impact of CF constructs on cost overrun [41,46]. Thus, prior to the application of SEM, a theoretical model is required to determine the relationship of the CF constructs to the cost overrun. The theoretical model is presented in Figure 2, showing both the factors and associated constructs. Each factor in each construct is coded and identified as an indicator that relates to the correspondent construct or "latent variable" with an arrow. The direction of the arrow being outwards from the constructs indicates that they are reflective, since a 
change in one single indicator (factor) does not affect other indicators, and they (indicators) are highly correlated and essentially interchangeable. At the same time, constructs (latent variables) are essential to cost overrun, since omitting one indicator means omitting one part of the construct, while they are all contributing to cost overrun [47]. This means that the contribution of each of the constructs to the total overrun will be determined, and the reflection (loading) of the four main constructs will be assigned to the corresponding factors. The model presented in Figure 2 measures the direct and indirect relationships between the four constructs and the overall cost overrun.

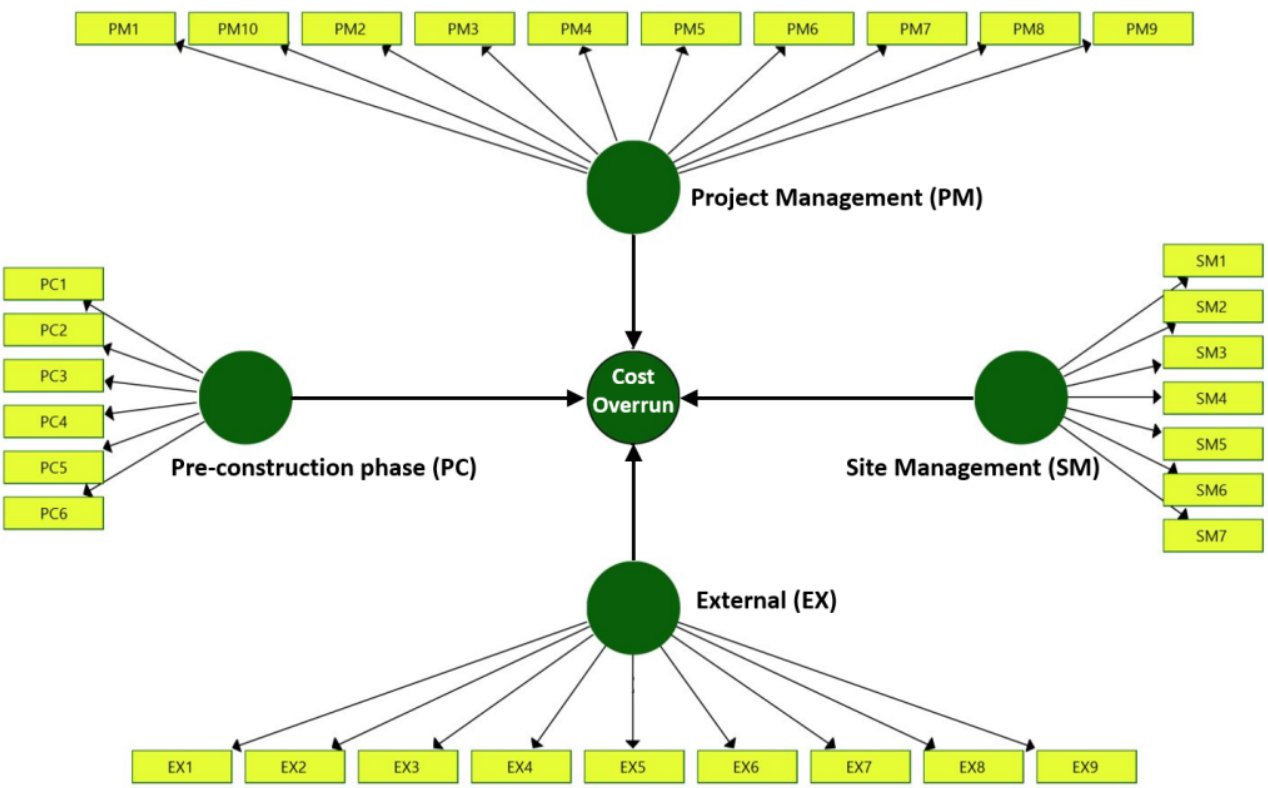

Figure 2. Theoretical model for determining factors affecting cost overrun.

Due to the small sample size and simplicity of the model, the Partial Least Squares method (PLS-SEM) was selected to analyze the data using SmartPLS version 3.0. PLS is a widely used method for estimating path coefficients in structural models, and is becoming significantly popular in management in recent years. Adopting a PLS approach to SEM has been recently recommended, and considered the most suitable method for examining causal relationships in the presence of constructs $[41,45]$. In addition, it has been demonstrated that SEM has better functionality than other multivariate techniques, including multiple regression, path analysis, and factor analysis $[41,45,46]$. One of the main advantages of PLS is its modeling ability for latent constructs under conditions of non-normality, and that it is practical for small to medium sample sizes [46,48].

\section{Results}

\subsection{Ranking of the Factors Affecting Cost Increase in the Planning Phase (PFs)}

This section presents the analysis of the results obtained from the respondents' attitudes towards the most influential parameters affecting cost increase in the planning phase. Prior to the RII analysis, reliability analysis was carried out, and Cronbach's $\alpha$ was determined to be 0.76 , indicating acceptable consistency. In addition, the Mahalanobis test identified no potential outliers. Table 4 shows the results obtained from RII analysis, as well as the mean and standard deviation. The factors are ranked according to RII, which gives the same ranking as if sorted by mean. However, RII, which is simply a scaled mean score for an item, is a more precise criterion to evaluate the importance of the factors. 
Table 4. Ranking of the most important parameters affecting cost increase in the planning phase (PFs).

\begin{tabular}{ccccc}
\hline Rank & Factor & RII & Mean & Std. Deviation \\
\hline 1 & Local wishes without cost responsibility & 0.818 & 4.0606 & 0.7044 \\
2 & Defective estimation & 0.794 & 3.9697 & 1.1035 \\
3 & Long processing time & 0.727 & 3.5455 & 1.1481 \\
4 & Those who get the benefit are not the ones who pay & 0.709 & 3.5455 & 1.0335 \\
4 & Changes in rules and regulations & 0.709 & 3.4545 & 1.0335 \\
5 & Project optimism & 0.697 & 3.4242 & 0.9364 \\
5 & Poor project management & 0.697 & 3.4242 & 1.1734 \\
5 & Lack of follow-up & 0.697 & 3.3939 & 1.1163 \\
6 & Changes in the society expectations & 0.661 & 3.2121 & 1.0828 \\
7 & City projects are detailed and costly to estimate & 0.655 & 3.1818 & 1.2613 \\
8 & Cost increases from QA1 to QA2 have no consequences & 0.642 & 3.1515 & 0.8704 \\
9 & Technological development & 0.588 & 2.9091 & 0.9139 \\
9 & Weak incentives to reduce planning time & 0.588 & 2.8485 & 1.0642 \\
10 & Little transparency & 0.576 & 2.8485 & 0.7124 \\
11 & Socio-economic profitability is of little importance & 0.558 & 2.7879 & 0.8572 \\
12 & Increased funding hides cost growth & 0.552 & 2.7576 & 0.8671 \\
13 & Changed/different staffing & 0.552 & 2.6970 & 0.9838 \\
\hline
\end{tabular}

The results show that the parameter local wishes without cost responsibility was ranked as the most important cost increase factor, with the RII value of 0.818 . Next, defective estimation and long processing time are placed as the second and third, with RII values of 0.794 and 0.727, respectively. These are followed by those who get the benefit are not the ones who pay and changes in rules and regulations as the fourth most important factors, with an RII value of 0.709 .

Project optimism together with poor project management and lack of follow-up were ranked as the fifth factor, with an RII value of 0.697 , and changes in society expectations was ranked as the sixth factor.

The factors changed/different staffing, increased funding hides cost growth, more value for money is of little importance, and little transparency were determined to be the four least influential factors, with the RII values of $0.473,0.552,0.552$ and 0.558 , respectively. This is perhaps reflective of adjustments to quality assurance protocols since 'increasing the socio-economic profitability' and 'increasing transparency' were among the main objectives of the quality assurance regime in Norway.

\subsection{Ranking of the Factors in the Construction Phase (CFs)}

Similar to the planning phase, respondents' attitudes towards the most influential parameters affecting cost overrun in the construction phase were analyzed. Considering the reliability of the factors, Cronbach's $\alpha$ was measured to be 0.93 . Data were assessed for multivariate outliers using a Mahalanobis Distance Test, and no multivariate outliers were identified [49]. The results of RII analysis for the CFs are presented in Table 5. Scope changes was determined to be the most important factor affecting cost overrun during the construction phase, with an RII value of 0.842 . The value of RII for market conditions was calculated to be 0.818 , as the second most important factor, followed by unforeseen ground conditions with an RII value of 0.806 .

On the contrary, delay in progress payment by the owner, deliberate underestimation of costs, and monopolization of special equipment were listed as the least influential factors on cost overrun, with RII values of $0.412,0.442$, and 0.455 respectively. 
Table 5. Ranking of the most important parameters affecting cost overrun in the construction phase (CFs).

\begin{tabular}{|c|c|c|c|c|c|}
\hline Rank & Factor & Description & RII & Mean & Std. Deviation \\
\hline 1 & PM2 & Scope changes & 0.842 & 4.212 & 0.820 \\
\hline 2 & EX4 & Market conditions & 0.818 & 4.091 & 1.011 \\
\hline 3 & EX3 & Unforeseen ground conditions & 0.806 & 4.030 & 0.847 \\
\hline 4 & PM10 & Conflicts between contractor and the owner & 0.752 & 3.758 & 0.751 \\
\hline 5 & PC1 & Forecasting errors (e.g., increasing prices) & 0.739 & 3.697 & 0.810 \\
\hline 6 & PM9 & Contractual claims (cost or time extension) & 0.697 & 3.485 & 0.939 \\
\hline 7 & PC2 & Delays in decision-making & 0.691 & 3.455 & 0.938 \\
\hline 7 & PC5 & Inadequate planning process & 0.691 & 3.455 & 0.971 \\
\hline 8 & SM1 & Insufficient site management and inspection & 0.648 & 3.242 & 0.969 \\
\hline 8 & EX9 & Project size & 0.648 & 3.242 & 1.032 \\
\hline 9 & PM3 & Improper scheduling & 0.636 & 3.182 & 0.882 \\
\hline 10 & PM6 & Poor project management & 0.624 & 2.758 & 0.663 \\
\hline 10 & PM8 & Lack of/slow communication between parties & 0.624 & 3.121 & 0.960 \\
\hline 10 & EX7 & Terrain condition & 0.624 & 3.121 & 0.960 \\
\hline 11 & SM2 & Lack of experience (in handling such projects) & 0.600 & 3.000 & 0.559 \\
\hline 12 & EX8 & Length of the road & 0.588 & 2.939 & 1.171 \\
\hline 13 & SM7 & Lack of incentives & 0.582 & 2.909 & 0.843 \\
\hline 13 & PC6 & Land and property acquisition challenges & 0.582 & 2.909 & 0.980 \\
\hline 14 & SM5 & Inefficient organizational structure & 0.570 & 2.848 & 0.870 \\
\hline 15 & SM6 & Rework due to poor material quality & 0.558 & 2.788 & 0.992 \\
\hline 16 & PM1 & Poor project design & 0.552 & 2.758 & 0.663 \\
\hline 16 & PM5 & Changes in materials types and specifications & 0.552 & 2.758 & 1.119 \\
\hline 17 & EX2 & Effect of bad weather (climate) & 0.527 & 2.636 & 1.113 \\
\hline 18 & EX1 & Labor unavailability or lack of skilled labor & 0.521 & 2.606 & 0.704 \\
\hline 19 & SM3 & Poor on-site financial control & 0.515 & 2.576 & 0.936 \\
\hline 19 & EX5 & Lack of resources & 0.515 & 2.576 & 1.062 \\
\hline 20 & SM5 & Inefficient use of resources & 0.503 & 2.515 & 0.870 \\
\hline 21 & PC3 & Strategic behavior (deliberate behavior) & 0.497 & 2.485 & 1.004 \\
\hline 22 & SM4 & Low labor productivity & 0.485 & 2.424 & 1.062 \\
\hline 23 & EX6 & Monopolization of special equipment & 0.455 & 2.273 & 1.008 \\
\hline 24 & PC4 & Deliberate underestimation of costs & 0.442 & 2.212 & 1.193 \\
\hline 25 & PM4 & Delay in progress payment by the owner & 0.412 & 2.061 & 0.827 \\
\hline
\end{tabular}

\subsection{Structural Relationship Model for CF Constructs}

The theoretical model (SEM-based), which was developed to determine the relevance of each of the main constructs (categorized CFs) to cost overrun, and the results are presented in this section. As stated before, the CFs were categorized into four main constructs:

(i) External-factors that are not under full control of project organization, such as the effect of bad weather and market conditions;

(ii) Pre-construction-factors mainly related to the planning or, more generally speaking, pre-construction phase, but their impact is revealed in the construction phase and affects the project's cost performance;

(iii) Project Management and Contractual Relationship-human-related factors that can barricade the smooth and stable process of the project;

(iiii) Contractor's Site Management-challenges related to financing, scheduling, supervising, or the problems derived from changing requirements.

The above-mentioned constructs were modeled in SmartPLS, and their relationship with cost overrun was measured. First, the internal consistency reliability of the model was tested by measuring Cronbach's alpha and Composite Reliability (CR). In addition, the convergent validity of the model was tested through assessing factor loadings and Average Variance Extracted (AVE). Item loadings for all the 32 factors are presented in Table 6 . The minimum values of item loading range between 0.5 and 0.7 . A value of 0.6 was used as the threshold, and only EX4, SM2, and SM7 had loading factors lower than $0.6(0.583,0.469$, 
and 0.353 , respectively) $[41,45,48]$. EX4 was kept since the loading factor was very close to 0.6 , and SM7, with the lowest loading factor, was deleted from further analysis. In the second round, it was observed that the deletion of SM7 resulted in a negligible increase in SM2's loading factor. However, as this was still below the threshold, SM2 was also removed from further analysis.

Table 6. Reliability and convergent validity of the constructs.

\begin{tabular}{|c|c|c|c|c|c|c|c|c|c|c|c|c|}
\hline \multirow{2}{*}{ Factor } & \multicolumn{4}{|c|}{ Iteration 1} & \multicolumn{4}{|c|}{ Iteration 2} & \multicolumn{4}{|c|}{ Iteration 3} \\
\hline & Loading & Alpha & CR & AVE & Loading & Alpha & CR & AVE & Loading & Alpha & CR & AVE \\
\hline EX1 & 0.735 & 0.785 & 0.834 & 0.581 & 0.735 & 0.785 & 0.834 & 0.581 & 0.735 & 0.785 & 0.834 & 0.581 \\
\hline EX2 & 0.83 & & & & 0.83 & & & & 0.83 & & & \\
\hline EX3 & 0.802 & & & & 0.802 & & & & 0.802 & & & \\
\hline EX4 & 0.583 & & & & 0.583 & & & & 0.583 & & & \\
\hline EX5 & 0.688 & & & & 0.688 & & & & 0.688 & & & \\
\hline EX6 & 0.774 & & & & 0.774 & & & & 0.774 & & & \\
\hline EX7 & 0.787 & & & & 0.787 & & & & 0.787 & & & \\
\hline EX8 & 0.726 & & & & 0.726 & & & & 0.726 & & & \\
\hline EX9 & 0.866 & & & & 0.866 & & & & 0.866 & & & \\
\hline PC1 & 0.877 & 0.82 & 0.87 & 0.729 & 0.877 & 0.82 & 0.87 & 0.729 & 0.877 & 0.82 & 0.87 & 0.729 \\
\hline PC2 & 0.751 & & & & 0.751 & & & & 0.751 & & & \\
\hline PC3 & 0.763 & & & & 0.763 & & & & 0.763 & & & \\
\hline PC4 & 0.697 & & & & 0.697 & & & & 0.697 & & & \\
\hline PC5 & 0.781 & & & & 0.781 & & & & 0.781 & & & \\
\hline PC6 & 0.726 & & & & 0.726 & & & & 0.726 & & & \\
\hline PM1 & 0.725 & 0.784 & 0.839 & 0.556 & 0.725 & 0.784 & 0.839 & 0.556 & 0.725 & 0.784 & 0.839 & 0.556 \\
\hline PM10 & 0.679 & & & & 0.679 & & & & 0.679 & & & \\
\hline PM2 & 0.694 & & & & 0.694 & & & & 0.694 & & & \\
\hline PM3 & 0.791 & & & & 0.791 & & & & 0.791 & & & \\
\hline PM4 & 0.811 & & & & 0.811 & & & & 0.811 & & & \\
\hline PM5 & 0.808 & & & & 0.808 & & & & 0.808 & & & \\
\hline PM6 & 0.826 & & & & 0.826 & & & & 0.826 & & & \\
\hline PM7 & 0.788 & & & & 0.788 & & & & 0.788 & & & \\
\hline PM8 & 0.762 & & & & 0.762 & & & & 0.762 & & & \\
\hline PM9 & 0.732 & & & & 0.732 & & & & 0.732 & & & \\
\hline SM1 & 0.813 & 0.671 & 0.794 & 0.452 & 0.804 & 0.728 & 0.812 & 0.502 & 0.826 & 0.742 & 0.828 & 0.568 \\
\hline SM2 & 0.469 & & & & 0.493 & & & & Omitted & & & \\
\hline SM3 & 0.874 & & & & 0.896 & & & & 0.869 & & & \\
\hline SM4 & 0.755 & & & & 0.791 & & & & 0.784 & & & \\
\hline SM5 & 0.727 & & & & 0.786 & & & & 0.831 & & & \\
\hline SM6 & 0.722 & & & & 0.757 & & & & 0.845 & & & \\
\hline SM7 & 0.353 & & & & Omitted & & & & Omitted & & & \\
\hline
\end{tabular}

Regarding Table 6, it can be observed that all AVE values, which are used to measure the common variance in a given construct, are higher than the recommended value of 0.5 , ranging from 0.556 to 0.729 [48]. Moreover, CR values, which describe the degree to which the construct factors indicate the latent construct, were observed to be higher than the recommended value of 0.7 [46,48]. Thereafter, discriminant validity was checked, and the AVE value of each construct was found to be larger than its corresponding correlation coefficients $[46,50]$.

The structural relationship model determines the direct and indirect relationships of each construct to cost overrun using regression coefficients $R^{2}$ and $\beta$, as presented in Figure 3. Moreover, the bootstrap procedure examined the significance of $\beta$ values in indirect relationships among the constructs. However, due to the simplicity of the model used in this study and given that the constructs are directly related to the overall cost overrun, only direct relationships were measured in the model fit [41,46]. According to previous studies $[45,46,48]$, the path relationships are assumed to be significant at 
$10 \%, 5 \%$, and $1 \%$ significance levels, while the $t$-values are higher than $1.65,1.96$, and 2.57 , respectively. In particular, the percentage of model variance extraction is shown by $R^{2}$, while path coefficients $(\beta)$ indicate the strength of the relationships between the constructs $[41,45]$. This means that the values of path coefficients shown in Figure 3 indicate the impact of each construct on cost overrun.

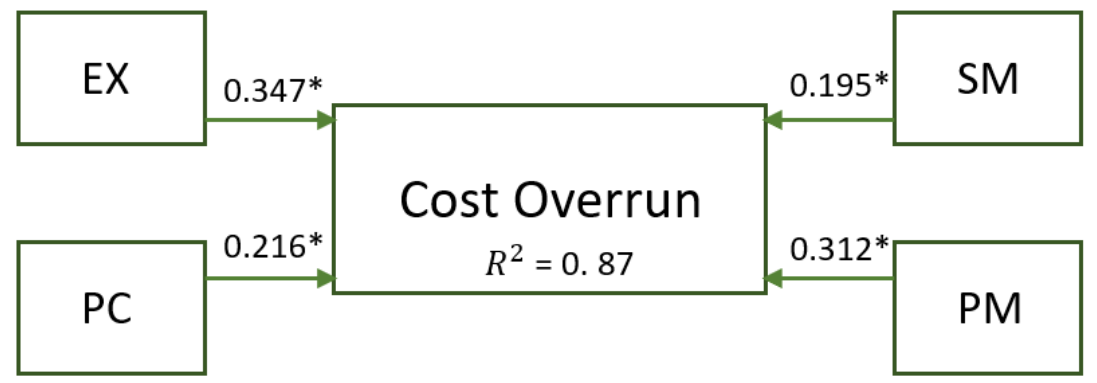

${ }^{*}$ Critical t-value: $2.58(\mathrm{P}<0.01)$

Figure 3. Results of the structural model.

As shown in Figure 3, $R^{2}$ is determined to be 0.87-higher than 0.26, which Cohen [51] believes indicates substantial explaining power. Regarding the path coefficients, it can be observed that all the constructs positively affected cost overrun, but they share different variance values. For instance, the construct EX has $\beta=0.347$, which means this construct significantly affects cost overrun compared to the others by explaining $34.7 \%$ of the variance in cost overrun. Second, PM shares $31.2 \%$ of the variance $(\beta=0.312)$ with respect to cost overrun. The value of $\beta$ was observed to be 0.216 and 0.195 for PC and SM constructs, respectively.

\section{Discussion}

This section discusses the results presented in the previous section, mainly the ranking of the most important factors affecting the cost inaccuracy in the planning and construction phases, and elaborates on the results obtained from PLS-SEM.

\subsection{Factors Affecting Cost Increase in the Planning Phase (PFs)}

Local wishes without cost responsibility was ranked as the most important factor, with an RII value of 0.818. A good example of this type of factor is the case of St Olav's Hospital in Trondheim, Norway (while not a transport project, this is still a state-funded project). The initiators and eventual owners of the project at the county level assumed that the state government would take responsibility for funding, and the cost increases would not stop the project based on previous state-funded hospital projects. However, within a few years, costs were increased from NOK 1 billion to NOK 12 billion, and if the state government had not curbed the cost increase through extensive hospital reform measures, the cost increases could have been much more [4,52]. Liabilities and incentives for cost control should be introduced at the early stages of planning to avoid cost escalations. The public sector relies on transparency in order to strengthen accountability. Therefore, government-funded projects should be selected based on high-quality information about the needs, benefits, costs, and risks.

Considering the factors of local wishes without cost responsibility (first), defective estimation (second), those who get the benefit are not the ones who pay (fourth), together with project optimism (fifth), it can be inferred that generally, inaccurate estimations in the phase of planning, together with local wishes and lack of responsibility, are the main reasons for cost increases in the planning phase. Sometimes, local promoters deliberately provide low-cost estimates to make it easier to gain acceptance for the project. Estimations are normally unrealistic, and on the contrary, benefits for the users and society are overestimated. As a result of underestimating the costs and overestimating the benefits, the chance of the project 
being accepted increases, and the project initiatives, which might have been reasonable and beneficial in the first place, grow in costs and become over-dimensioned, due to the requirements additionally introduced after the initial approval of the project. In contrast, if the actual costs are presented, the project may be rejected at the early stages $[52,53]$.

These results agree with previous studies, which state that politicians play a role in the planning process. Road administrations in some regions are more politicized than others, which can also result in misleading cost information being given to Parliament, which eventually leads to cost increase. In addition, competition exists between different parties in some regions to keep their policies at the forefront [23]. As another example, Volden [53] evaluated nine large-scale projects' planning stages, and found that substantial resources were spent just on lobbying.

The fifth-place ranking belonged to project optimism, together with poor project management and lack of follow-up, with an RII value of 0.697. Although these three parameters are still among the most important in the respondents' opinions, project handling in the planning phase in Norway has been significantly improved since the quality assurance regime was introduced in 2000 and expanded in 2005. This implies that both the economic appraisals and cost estimates of large government projects must be scrutinized by external consultants before projects are allowed to proceed to the next planning phase [54]. This governance regime ensures that plans and estimates are subjected to an outside view, which may reduce the risk of over-optimism and strategic behavior.

Project planning in Norway is an open and communicative process that requires that all stakeholders must be consulted. Local authorities must grant planning permission before the government can approve a final budget. This increases the risk of both a misalignment of incentives and that the process may take longer than planned. As time passes, the expectations of society increase, and our acceptance of adverse environmental and social effects decreases. In addition to the fact that it may stretch the planning phase out, it may cause unwanted cost increases [55].

\subsection{Factors Affecting Cost Overrun in the Construction Phase (CFs)}

Ranked first in this study, changes in the scope of the projects has been listed among the main reasons for cost overrun indicated within the literature. Ascher [56] found that about $40-90 \%$ of the total cost overrun can be explained by three factors alone: scope change, impact of inflation, and delay. In a more recent study done by Lee in 2008, the author concluded that changes in scope, delays during construction, unreasonable estimations, and adjustments of project costs are the main reasons of cost overrun [57].

One of the main reasons that market conditions is ranked second is that Norway has experienced three different periods of high market volatility since 2000 (i.e., inflation, and as a result increases in materials prices, in 2004-2005; the world crisis in 2008-2009, and the oil price drop in 2015-2016). Norway's economy is highly dependent on the oil market, and fluctuations in the price of oil can result in an unstable and volatile market. This has also been investigated by Dahl et al. [58], who found a clear relationship between the increase in oil prices and cost overruns.

Unforeseen ground conditions was observed to be the third most important factor, and has been among the most important factors in the literature, but its importance is even higher in Norway. Fjord and mountain landscapes in the western and eastern regions, and to a lesser extent the central region, make the topography of Norway challenging for infrastructure construction. Most of the population is located in areas with large marine deposits, making road construction vulnerable to quick clay and unstable geological conditions. Therefore, it can be deduced that the first three factors should be considered as serious uncertainties in the early planning phases, which may lead to unwanted time or cost overruns.

In the opinion of Norwegian experts, conflicts between contractor and the owner was ranked as fourth, with an RII value of 0.752 . Generally, Norwegian work culture is egalitarian and independent, meaning that people are given enough freedom to work in the areas of their responsibility. The system is also based on trust, and people usually prefer 
not to be told in detail how to do their job. However, conflicts and disputes in the construction industry in Norway have been increasing in recent years. According to a study carried out by Sabri et al. [59], tender specification and contract understanding, final settlement payment, low-priced contracts, and changes in the project were the most influencing parameters resulting in conflicts and disputes. Among them, tender specifications and contract understanding were the most influential causes of conflicts in Norway, followed by disagreements on final settlements, usually issued by the public owner. They recommend introducing a clear dispute management pattern for investments in large-scale Norwegian infrastructure projects [59].

Forecasting errors is another factor, similar to market conditions, that should be considered in uncertainty analysis from the early planning phases. This is a factor that stems from underestimation during the planning phase, affecting the cost overrun in the construction phase. In such a case, the government has two options: either finance the project for the additional requested budget, or stop the project. However, if the estimations were more precise, the government could make another decision, such as project modification. Increasing transparency and logging all project cost estimations from the early stages of planning could be a solution for increasing the precision of the estimation and reducing the risk of forecasting errors. Nevertheless, the analysis methods in this study could not measure these effects, which could be a potential area for further research.

Project size and length of the road were evaluated in this study, and were ranked as eighth and twelfth. Previous studies showed that project size, which is defined according to the budget allocated for the project, might have an impact on the magnitude of cost overrun, as the larger the project, the higher amount of cost overrun. However, the findings are inconclusive, but it can be regarded as an important parameter according to the obtained results.

Delay in progress payment by the owner, deliberate underestimation of costs, and monopolization of special equipment were listed as the least influential factors on cost overrun. It was expected that monopolization of equipment can be more influential in developing countries, in countries with lower GDP, or in places where the management and governance of the public projects is not transparent, and there might be a risk of corruption. Deliberate underestimation of costs and strategic behavior (deliberate behavior) were also among the lower-ranked factors. This indicates that in contrast to some of the available research, including that by Cantarelli et al. [20], who categorized them as economical explanations for cost overrun, these factors do not play an important role in Norway.

\subsection{CF Constructs}

Concerning the SEM analysis and model result in Figure 3, and with regard to the second research question, it can be inferred that external factors have the largest impact on cost overrun within this study. As previously stated, external factors are not entirely under the control of humans, such as the effect of bad weather or market conditions. However, it is possible to consider uncertainties that originate from external factors in the planning process. As of now, cost estimations, particular to Norway, are calculated based on stochastic (probability-based) estimations in the early planning phases. Carrying out stochastic estimations, either through mathematical analytical methods or simulation tools, results in a cumulative probability distribution of investment costs. The estimation process produces a tornado diagram that ranks different uncertainties according to their impact on total costs, which can then result in further oversight during the construction phase.

The project management and contractual relationship construct was determined to be the second most important group of factors affecting cost overrun. As mentioned previously and discussed in Section 5.2, this construct primarily includes human-related factors that can directly affect smooth and stable project governance. Risk factors in this construct mostly originate from tender specification and contract misunderstanding, improper scheduling/delayed final settlement/payment, low-priced contracts, and changes in the project's scope. For example, conflicts between contractor and the owner and contractual claims 
(cost or time extension) were ranked as fourth and sixth among the CFs, respectively. Therefore, improving and better clarifying tender specifications and contract understanding may reduce conflicts and disputes, which have been recently increasing in Norway.

Site management factors have the least impact on cost overrun. This means that contractors are performing justifiably in Norway, according to the respondents, who notably did not include contractors themselves.

According to the model results, pre-construction factors have the second lowest impact on cost overrun. These are factors that reveal themselves during the construction phase, but stem from the planning phase. Considering the previous rankings (in Table 5), some of the factors, including forecasting errors (e.g., increasing prices), delays in decision-making, and inadequate planning process, rank rather highly (fifth, seventh and seventh, respectively). While others, specifically strategic behavior (deliberate behavior) and deliberate underestimation of costs, are listed among the least important factors. Thus, there is not necessarily a consistent trend among the factors within this construct, and the low-ranking factors can reduce the overall impact of the construct as a whole.

\section{Conclusions}

Cost performance, specifically cost overrun, is an important topic within transportation economy and project management. It is essential to realize what factors affect cost overrun during both construction and planning phases. Determining these factors will not only improve the cost performance and improve the success level of the project, but also helps to manage and ensure the proper use of resources.

Considering sustainability, the main focus of this study was on the economic aspect of sustainability, focusing on risk factors that can affect the cost performance of largescale road projects in order to curb cost overrun risks. Thus, increased knowledge of factors affecting cost performance is important to attain economically sustainable project management. Moreover, it can also result in the better use of resources, and thus the further preservation of the environment.

This study investigated the most important factors affecting cost overrun in the planning and construction phases using data from Norway. Using data from one country, where projects are planned and implemented in a consistent manner, ensures a more robust assessment of causes than studies based on data collected from different countries and from different time periods. This paper enhances the past research by introducing a new set of factors that may occur during the planning phase and affect the final cost performance of the project, as well as the most influential factors in the construction phase affecting cost overrun in Norway. Projects go through different stages in their development and delivery, and the causes of cost increase and overrun may differ as time proceeds. To identify root causes, studies should therefore distinguish between projects' front-end and delivery. To this aim, a questionnaire survey was distributed to various relevant people who have been involved in at least in one large-scale road project in Norway. The main findings of the study can be summarized as follows:

- Local wishes without cost responsibility, defective estimation, long processing time, those who benefit are not the ones who pay, and changes in rules and regulations are the main factors that can result in cost overrun in the planning phase. This suggests that from a political perspective, there may be arguments for better aligning the interests of project owners and local stakeholders, for example, through a mechanism for mandatory local contribution. Furthermore, despite progress in improving the quality of project front-end management over the last two decades, there is still potential for improving efficiency by improving cost estimation methodologies that better capture the risks in the early stages of appraisal and planning. Likewise, changed/different staffing, increased funding hides cost growth, and socio-economic profitability is of little importance are among the least influential factors, indicating that the planning process in some of the regions might be politicized. In addition, long processing time should be considered as a 
serious uncertainty even in the planning phase, which may result in an increase in cost estimations;

- Scope changes, market conditions, and unforeseen ground conditions are the most influential factors on cost overrun in the construction phase, according to the experts' opinions in Norway. This is in agreement with previous studies, as these three factors have been among the most critical uncertainties in large infrastructure projects worldwide. In addition, within the construction phase, delay in progress payment by the owner, deliberate underestimation of costs, and monopolization of special equipment are the factors with the least influence on cost overrun;

- $\quad$ Factors affecting cost overrun during the construction phase were categorized into four main constructs-external, contractor's site management, pre-planning, and project management and contractual relationship were modeled in SmartPLS version 3.0 to determine and compare their impact on cost overrun. External factors-generally uncertain factors with less human controllability-had the greatest impact on cost overrun. This indicates that although cost estimations in Norway are based on stochastic estimations, there is still room for improvement. However, according to the respondents, planning phase factors did not strongly affect cost overrun during construction despite the suggestions in the previous literature.

The results of this study create knowledge on risk factors that can affect cost inaccuracy in both the planning and construction phases, and the relationships between them. Investigating such factors in the planning phase and their impact on the construction phase and overall cost overrun has not been considered in the literature yet. This research also highlights that studies of cost overrun address economic sustainability within project management.

Finally, it should be mentioned that this study also has limitations. First, the results of this study are not directly applicable to other countries, and similar studies should be carried out in individual countries. However, the methodology used in this study can be utilized for other similar studies. Second, the small sample size was the limitation of this study, which made the use of SEM challenging. However, the PLS-based method was used in this study, which is recommended in the literature for small sample sizes. In addition, with a bigger sample size, it could have been possible to cover more attitudes (e.g., contractors) in the research, and reduce the risk of biased answers. This could be suggested for further research, together with an assessment of the planning phase as a highly relevant parameter that can influence the cost performance of the project.

Author Contributions: Conceptualization, A.F.M.; methodology, A.F.M., K.P., J.O. and M.W.; software, validation and formal analysis, A.F.M.; writing-original draft preparation, A.F.M.; writingreview and editing, K.P., J.O. and M.W.; supervision, K.P. and J.O. All authors have read and agreed to the published version of the manuscript.

Funding: This research was funded by the Norwegian Public Roads Administration.

Informed Consent Statement: Informed consent was obtained from all subjects involved in the study.

Data Availability Statement: The data presented in this study are available on request from the corresponding author. The data are not publicly available due to confidentiality.

Conflicts of Interest: The authors declare no conflict of interest.

\section{References}

1. Martínez-Perales, S.; Ortiz-Marcos, I.; Juan Ruiz, J.; Lázaro, F.J. Using certification as a tool to develop sustainability in project management. Sustainability 2018, 10, 1408. [CrossRef]

2. Uribe, D.F.; Ortiz-Marcos, I.; Uruburu, Á. What is going on with stakeholder theory in project management literature? A symbiotic relationship for sustainability. Sustainability 2018, 10, 1300. [CrossRef]

3. Eliasson, J.; Börjesson, M.; Odeck, J. and Welde, M. Does Benefit-Cost Efficiency Influence Transport Investment Decisions? J. Transp. Econ. Policy 2015, 49, 377-396. 
4. Volden, G.H. Public funding, perverse incentives, and counterproductive outcomes. Int. J. Manag. Proj. Bus. 2019, 12, 466-486. [CrossRef]

5. Rodríguez-Rivero, R.; Ortiz-Marcos, I.; Ballesteros-Sánchez, L.; Martínez-Beneitez, X. Identifying Risks for Better Project Management between Two Different Cultures: The Chinese and the Spanish. Sustainability 2020, 12, 7588. [CrossRef]

6. Rodríguez-Rivero, R.; Ortiz-Marcos, I.; Romero, J.; Ballesteros-Sánchez, L. Finding the links between risk management and project success: Evidence from international development projects in Colombia. Sustainability 2020, 12, 9294. [CrossRef]

7. Norge, R. Grunnlagsdokument Nasjonal transportplan 2018-2029. Oslo. Zugriff am 2016, 27, 2016.

8. Cantarelli, C.C.; van Wee, B.; Molin, E.J.; Flyvbjerg, B. Different cost performance: Different determinants?: The case of cost overruns in Dutch transport infrastructure projects. Transp. Policy 2012, 22, 88-95. [CrossRef]

9. Odeck, J. Variation in cost overruns of transportation projects: An econometric meta-regression analysis of studies reported in the literature. Transportation 2019, 46, 1345-1368. [CrossRef]

10. Plebankiewicz, E. Model of predicting cost overrun in construction projects. Sustainability 2018, 10, 4387. [CrossRef]

11. Plebankiewicz, E.; Wieczorek, D. Prediction of cost overrun risk in construction projects. Sustainability 2020, 12, 9341. [CrossRef]

12. Pickrell, D.H. Urban Rail Transit Projects: Forecast Versus Actual Ridership and Costs [October 1989]; (No. UMTA-MA-08-9021-89-1); Urban Mass Transportation Administration: Washington, DC, USA, 1990.

13. Skamris, M.K.; Flyvbjerg, B. Inaccuracy of traffic forecasts and cost estimates on large transport projects. Transp. Policy 1997, 4, 141-146. [CrossRef]

14. Flyvbjerg, B.; Holm, M.S.; Buhl, S. Underestimating costs in public works projects, error or lie? J. Am. Plan. Assoc. 2002, 68, 279-295. [CrossRef]

15. Odeck, J. Cost overruns in road construction-What are their sizes and determinants? Transp. Policy 2004, 11, 43-53. [CrossRef]

16. Nijkamp, P.; Ubbels, B. How reliable are estimates of infrastructure costs? A comparative analysis. Int. J. Transp. Econ. Riv. Int. Econ. Trasp. 1999, 26, 23-53.

17. Siemiatycki, M. Academics and auditors: Comparing perspectives on transportation project cost overruns. J. Plan. Educ. Res. 2009, 29, 142-156. [CrossRef]

18. Makovšek, D. Public-private partnerships, traditionally financed projects, and their price. J. Transp. Econ. Policy JTEP 2013, 47, 143-155.

19. Odeck, J. Do reforms reduce the magnitudes of cost overruns in road projects? Statistical evidence from Norway. Transp. Res. A Policy Pract. 2014, 65, 68-79. [CrossRef]

20. Cantarelli, C.C.; Molin, E.J.E.; van Wee, B.; Flyvbjerg, B. Characteristics of cost overruns for Dutch transport infrastructure projects and the importance. Transp. Policy 2012, 22, 49-56. [CrossRef]

21. Shehu, Z.; Endut, I.R.; Akintoye, A. Factors contributing to project time and hence cost overrun in the Malaysian construction industry. J. Financ. Manag. Prop. Constr. 2014, 19, 55-75. [CrossRef]

22. Love, P.E.; Sing, C.P.; Wang, X.; Irani, Z.; Thwala, D.W. Overruns in transportation infrastructure projects. Struct. Infrastruct. Eng. 2014, 10, 141-159. [CrossRef]

23. Welde, M.; Odeck, J. Cost escalations in the front-end of projects-empirical evidence from Norwegian road projects. Transp. Rev. 2017, 37, 612-630. [CrossRef]

24. Cantarelli, C.C.; Flybjerg, B.; Molin, E.J.; Van Wee, B. Cost overruns in large-scale transportation infrastructure projects: Explanations and their theoretical embeddedness. arXiv 2013, arXiv:1307.2176.

25. Long, N.D.; Ogunlana, S.; Quang, T.; Lam, K.C. Large construction projects in developing countries: A case study from Vietnam. Int. J. Proj. Manag. 2004, 22, 553-561. [CrossRef]

26. Majid, I.A. Causes and Effects of delays in ACEH Construction Industry. Doctoral Thesis, Universiti Teknologi Malaysia, Skudai, Malaysia, 2006.

27. Ameh, O.J.; Soyingbe, A.A.; Odusami, K.T. Significant Factors Causing Cost Overruns in Telecommunication Projects in Nigeria; University of Lagos: Lagos, Nigeria, 2010.

28. Azhar, N.; Farooqui, R.U.; Ahmed, S.M. Cost overrun factors in construction industry of Pakistan. In Proceedings of the First International Conference on Construction in Developing Countries (ICCIDC-I), Advancing and Integrating Construction Education, Research \& Practice, Karachi, Pakistan, 4-5 August 2008; pp. 499-508.

29. Al-Juwairah, Y.A. Factors Affecting Construction Costs in Saudi Arabia. Doctoral Thesis, King Fahd University of Petroleum and Minerals, Dhahran, Saudi Arabia, 1997.

30. Doloi, H.; Sawhney, A.; Iyer, K.C.; Rentala, S. Analysing factors affecting delays in Indian construction projects. Int. J. Proj. Manag. 2012, 30, 479-489. [CrossRef]

31. Fugar, F.D.; Agyakwah-Baah, A.B. Delays in building construction projects in Ghana. Australas. J. Constr. Econ. Build. 2010, 10, 128-141. [CrossRef]

32. Al-Kharashi, A.; Skitmore, M. Causes of delays in Saudi Arabian public sector construction projects. Constr. Manag. Econ. 2009, 27, 3-23. [CrossRef]

33. Assaf, S.A.; Al-Hejji, S. Causes of delay in large construction projects. Int. J. Proj. Manag. 2006, 24, 349-357. [CrossRef]

34. Sambasivan, M.; Soon, Y.W. Causes and effects of delays in Malaysian construction industry. Int. J. Proj. Manag. 2007, 25, 517-526. [CrossRef]

35. Odeh, A.M.; Battaineh, H.T. Causes of construction delay: Traditional contracts. Int. J. Proj. Manag. 2002, 20, 67-73. [CrossRef] 
36. Sweis, G.; Sweis, R.; Hammad, A.A.; Shboul, A. Delays in construction projects: The case of Jordan. Int. J. Proj. Manag. 2008, 26, 665-674. [CrossRef]

37. Yates, J.K. Construction decision support system for delay analysis. J. Constr. Eng. Manag. 1993, 119, 226-244. [CrossRef]

38. Yang, J.B.; Ou, S.F. Using structural equation modeling to analyze relationships among key causes of delay in construction. Can. J. Civ. Eng. 2008, 35, 321-332. [CrossRef]

39. Toor, S.U.R.; Ogunlana, S.O. Problems causing delays in major construction projects in Thailand. Constr. Manag. Econ. 2008, 26, 395-408. [CrossRef]

40. Rossi, P.H.; Wright, J.D.; Anderson, A.B. Sample surveys: History, current practice, and future prospects. In Handbook of Survey Research; University of Massachusetts, Academic press: Amherst, MA, USA, 1983; pp. 1-20.

41. Memon, A.H.; Rahman, I.A. Analysis of cost overrun factors for small scale construction projects in Malaysia using PLS-SEM method. Mod. Appl. Sci. 2013, 7, 78. [CrossRef]

42. Larsen, J.K.; Shen, G.Q.; Lindhard, S.M.; Brunoe, T.D. Factors affecting schedule delay, cost overrun, and quality level in public construction projects. J. Manag. Eng. 2016, 32, 04015032. [CrossRef]

43. Love, P.E. Influence of project type and procurement method on rework costs in building construction projects. J. Constr. Eng. Manag. 2002, 128, 18-29. [CrossRef]

44. Love, P.E.; Edwards, D.J.; Watson, H.; Davis, P. Rework in civil infrastructure projects: Determination of cost predictors. J. Constr. Eng. Manag. 2010, 136, 275-282. [CrossRef]

45. Nguyen-Phuoc, D.Q.; Phuong Tran, A.T.; Nguyen, T.V.; Le, P.T.; Su, D.N. Investigating the complexity of perceived service quality and perceived safety and security in building loyalty among bus passengers in Vietnam-a PLS-SEM approach. Transp. Policy 2021, 101, 162-173. [CrossRef]

46. Ali, F.; Kim, W.G.; Ryu, K. The effect of physical environment on passenger delight and satisfaction: Moderating effect of national identity. Tour. Manag. 2016, 57, 213-224. [CrossRef]

47. Diamantopoulos, A.; Winklhofer, H.M. Index construction with formative indicators: An alternative to scale development. $J$. Mark. Res. 2001, 38, 269-277. [CrossRef]

48. Hair, J.F., Jr.; Hult, G.T.M.; Ringle, C.; Sarstedt, M. A Primer on Partial Least Squares Structural Equation Modeling (PLS-SEM); Sage Publications: Thousand Oaks, CA, USA, 2016.

49. Tabachnick, B.G.; Fidell, L.S. Using Multivariate Statistics, 6th ed.; Pearson: Boston, MA, USA, 2013.

50. Fornell, C.; Larcker, D.F. Evaluating structural equation models with unobservable variables and measurement error. J. Mark. Res. 1981, 18, 39-50. [CrossRef]

51. Cohen, J. Statistical Power Analysis for the Social Sciences; Erlbaum: Hillsdale, NJ, USA, 1988.

52. Odeck, J. What determines decision-makers' preferences for road investments? Evidence from the Norwegian road sector. Transp. Rev. 2010, 30, 473-494. [CrossRef]

53. Volden, G.H. Up-Front Governance of Major Public Investment Projects. Doctoral Thesis, Norwegian University of Science and Technology, Trondheim, Norway, 2019.

54. Odeck, J.; Welde, M.; Volden, G.H. The impact of external quality assurance of costs estimates on cost overruns: Empirical evidence from the Norwegian road sector. Eur. J. Transp. Infrastruct. Res. 2015, 15, 286-303.

55. Flyvbjerg, B.; Skamris Holm, M.K.; Buhl, S.L. How common and how large are cost overruns in transport infrastructure projects? Transp. Rev. 2003, 23, 71-88. [CrossRef]

56. Ascher, $\mathrm{W}$. The ambiguous nature of forecasts in project evaluation: Diagnosing the over-optimism of rate-of-return analysis. Int J. Forecast. 1993, 9, 109-115. [CrossRef]

57. Lee, J.K. Cost overrun and cause in Korean social overhead capital projects: Roads, rails, airports, and ports. J. Urban Plan. Dev. 2008, 134, 59-62. [CrossRef]

58. Dahl, R.E.; Lorentzen, S.; Oglend, A.; Osmundsen, P. Pro-cyclical petroleum investments and cost overruns in Norway. Energy Policy 2017, 100, 68-78. [CrossRef]

59. Sabri, O.K.; Lædre, O.; Bruland, A. Why conflicts occur in roads and tunnels projects in Norway. J. Civ. Eng. Manag. 2019, 25, 252-264. [CrossRef] 